\title{
KINETIC MEASUREMENTS DURING TRANSIENT FILM GROWTH ON ZINC
}

\section{Yun Chen}

Department of Engineering Physics, University of Wisconsin-Madison, Wisconsin 53706, USA

Rui F. M. Lobo

Institute of Materials and Surfaces Science and Engineering, Faculty of Science and Technology, New University of Lisbon, 2829-516 Caparica, Portugal

\section{Diogo M. F. Santos and César A. C. Sequeira*}

Institute of Materials and Surfaces Science and Engineering, Department of Chemical and Biological Engineering, Instituto Superior Técnico, Technical University of Lisbon, Av. Rovisco Pais, 1049-001 Lisboa, Portugal

Recebido em 10/4/08; aceito em 6/10/08; publicado na web em 26/1/09

\begin{abstract}
The electrochemical behaviour of zinc has been extensively studied in alkaline and acid media, but only a few studies have been reported in neutral solutions, particularly in deaerated media. Zinc passivation in neutral medium and the effect of the $\mathrm{ClO}_{4}^{-}$ion on the nucleation and growth of the passive layer is studied in this paper by a transient technique at different electrolyte concentrations and applied potentials. $\mathrm{ZnO}$ growth rate was shown to decrease with increasing electrolyte concentration. Moreover, passive layer growth occurred followed by pitting nucleation and growth. Film growth and pit nucleation are explained by means of the Macdonald and Engell-Stolica models.
\end{abstract}

Keywords: zinc; passivation; pitting.

\section{INTRODUCTION}

Zinc, one of the most widely used metals, cannot be worn in applications under applied stress due to its low creep resistance. It recrystallises rapidly after deformation at room temperature and, thus, cannot be work-hardened at room temperature. Creep resistance and recrystallisation temperature may be increased through alloying. ${ }^{1}$ In the past decades, research on various aspects of corrosion of zinc has generated much technical information. Most of this wealth of information has been systematically and critically reviewed. ${ }^{2}$

The electrochemical properties of zinc are of most importance in its production and applications. For instance, electrowinning in zinc refining, electroplating in the production of zinc coatings, zinc batteries for energy storage, and zinc anodes for corrosion protection are all based essentially on zinc electrochemical properties. These properties include the relatively active position in the electromotive force series, fast and reversible dissolution/deposition kinetics, high overpotential for hydrogen evolution, and formation of passive film in slightly alkaline solutions. ${ }^{2}$

The electrochemical behaviour of zinc has been studied in alkaline media $^{3}$ due to the need of developing primary cells with high dissolution electrode activity and without passivation; it has also been studied in acid media ${ }^{4}$ and slightly acid solutions ${ }^{5}$ due to its applications in the $\mathrm{Cl}_{2} / \mathrm{Zn}$ and Leclanché's batteries. Despite its extensive use in galvanised steels, ${ }^{6}$ few studies have been reported in neutral solutions, particularly in deaerated media. ${ }^{5}{ }^{7}$ In neutral solutions, with chemical agents that are not electrochemically reactive and that do not form insoluble salts or complex ions with zinc, the corrosion rate of zinc is not very different from that in distilled water. However, there are several species (e.g. certain anions) that greatly influence the corrosion processes of zinc in solutions. Láng and Horányi ${ }^{8,9}$ demonstrated that the reduction of $\mathrm{ClO}_{4}^{-}$ions takes place during the spontaneous dissolution of $\mathrm{Zn}$ in $\mathrm{HClO}_{4}$. They furnished unambiguous evidence that such reduction leads to the formation of aggressive chloride ions

*e-mail: cesarsequeira@ist.utl.pt
$\mathrm{ClO}_{4}^{-}+4 \mathrm{H}_{2} \mathrm{O}+8 \mathrm{e}^{-} \rightarrow \mathrm{Cl}^{-}+8 \mathrm{OH}^{-}$

which play an important role in the passive layer formation as well as in the pitting process. In the absence of oxygen, the perchlorate ion adsorbs on the electrode surface and enhances the chemical dissolution of the interior $\mathrm{ZnO}$ layer to form $\mathrm{Zn}^{2+}(\mathrm{aq}){ }^{10,11}$ Moreover, its reduction promotes the formation of the less protective exterior passive layer as a result of the high amount of $\mathrm{OH}^{-}$produced from reaction (1). The formation of a thicker less protective exterior layer and a thinner interior one in absence of $\mathrm{O}_{2}$ is consistent with the nucleation and growth of pitting corrosion products. ${ }^{12}$ The aggressiveness of the $\mathrm{ClO}_{4}^{-}$ion towards the passivated $\mathrm{Zn}$ electrode in a neutral medium is studied in this paper by potentiostatic current-time transients at different electrolyte concentrations and applied potentials. Kinetic parameters were derived for passive layer growth, pit nucleation and its growth. The phenomenon of passivity, the electrochemistry of passivation, the models for pit initiation leading to passive film breakdown, and the kinetics of pit growth can be found in a number of sources. ${ }^{13-15}$ In the present study, the nucleation rate increases with increasing electrolyte concentration and anodic applied potential. Film growth and pit nucleation are explained by means of the Macdonald and Engell-Stolica models. ${ }^{16,17}$

\section{EXPERIMENTAL}

The working electrode was a disk made from a zinc rod (Aldrich, $99.999 \%$ ), with a geometric useful area of $0.243 \mathrm{~cm}^{2}$, embedded in an epoxy resin. At the beginning of each electrochemical experiment, the electrode was polished with 800 grade emery paper under running water conditions and then thoroughly rinsed with purified water and dried with absorbent paper. A platinum sheet of $2 \mathrm{~cm}^{2}$ geometric area was used as counter electrode and a saturated calomel electrode as reference, to which all potentials are referred. To avoid contamination with $\mathrm{Cl}^{-}$ions, the reference electrode was connected to the working electrode through a bridge filled with the solution under test, the top of the bridge being pressed against the electrode surface to minimise 
the IR drop of the solution. The electrolyte solutions (0.001 - $0.1 \mathrm{M}$ $\mathrm{KClO}_{4}$ neutral solutions) were prepared from purified water (MilliQ system) and $\mathrm{KClO}_{4}$ (SIGMA, ACS Reagent, 99\%). The solutions were deaerated with $\mathrm{N}_{2}$ before each experiment, and during the experiments $\mathrm{N}_{2}$ was passed over the non-stirred solutions. Tests for $\mathrm{Cl}^{-}$ions in the $\mathrm{ClO}_{4}^{-}$solutions revealed the absence of chloride ions after each experimental run.

The potentiostatic current-time transients were recorded by polarising potentiodynamically the working electrode from the starting potential of $-1800 \mathrm{mV} v s$. SCE in the positive direction with the scan rate of $50 \mathrm{mVs}^{-1}$ to a potential limit $\mathrm{E}_{\mathrm{a}}(\leq-500 \mathrm{mV} v$ s. SCE) at which the current transients were recorded for $2 \mathrm{~min}$. The selection of the $-1800 /-500 \mathrm{mV}$ potential window was dictated by previous cyclic voltammetry measurements that showed an active/passive transition within that anodic span (Figure 1). A potentiostat/galvanostat (EG\&G model 273) and a personal computer were used. Each experiment was performed with a freshly prepared solution and a newly polished set of electrodes. All measurements were carried out at room temperature $\left(25 \pm 0.5^{\circ} \mathrm{C}\right)$.

\section{RESULTS AND DISCUSSION}

Figure 1 shows a potentiodynamic current-potential curve for stationary zinc electrode in deaerated $0.1 \mathrm{M} \mathrm{KClO}_{4}$ solution, at a scan rate of $1 \mathrm{mVs}^{-1}$. Its inspection reveals an active-passive transition prior to a certain critical breakdown potential, which is shown to be $-700 \mathrm{mV}$ vs. SCE. This value shifts to more anodic values when the potential is changed at higher scan rates, which explains why the potential window attained $\mathrm{E}_{\mathrm{a}}$ values as high as $-500 \mathrm{mV}$ vs. SCE.

SEM observations (Figure 2) confirmed the different nature of the zinc surface, from its pretreated situation (A) to its anodic polarisation showing passivity (B), starting of pit nucleation (C), and growth of pits (D).

The potentiostatic current-time transients for $\mathrm{Zn}$ in $\mathrm{KClO}_{4}$ solutions with concentrations ranging from 0.001 to $0.1 \mathrm{M}$ at various potential limits $\mathrm{E}_{\mathrm{a}}$ (within the passive region) were recorded. Figure 3 represents some of these transients at $\mathrm{E}_{\mathrm{a}}=-950 \mathrm{mV}$ vs. SCE.

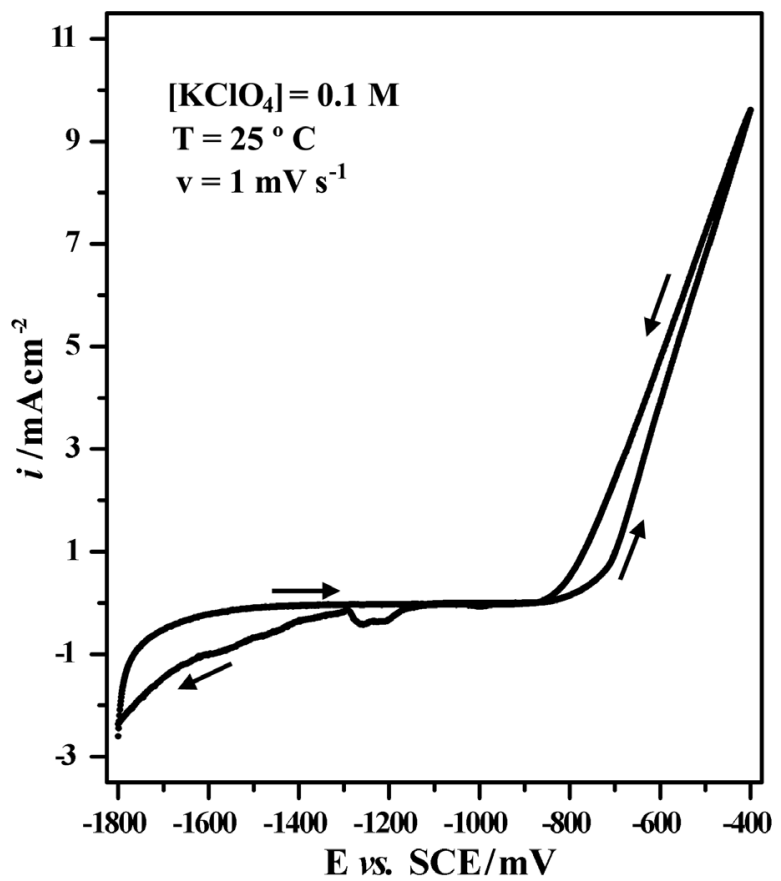

Figure 1. Typical potentiodynamic current-potential curve for stationary $\mathrm{Zn}$ electrode in deaerated $0.1 \mathrm{M} \mathrm{KClO}_{4}$ at $25^{\circ} \mathrm{C}$ and scan rate of $1 \mathrm{mV} \mathrm{s} \mathrm{s}^{-1}$

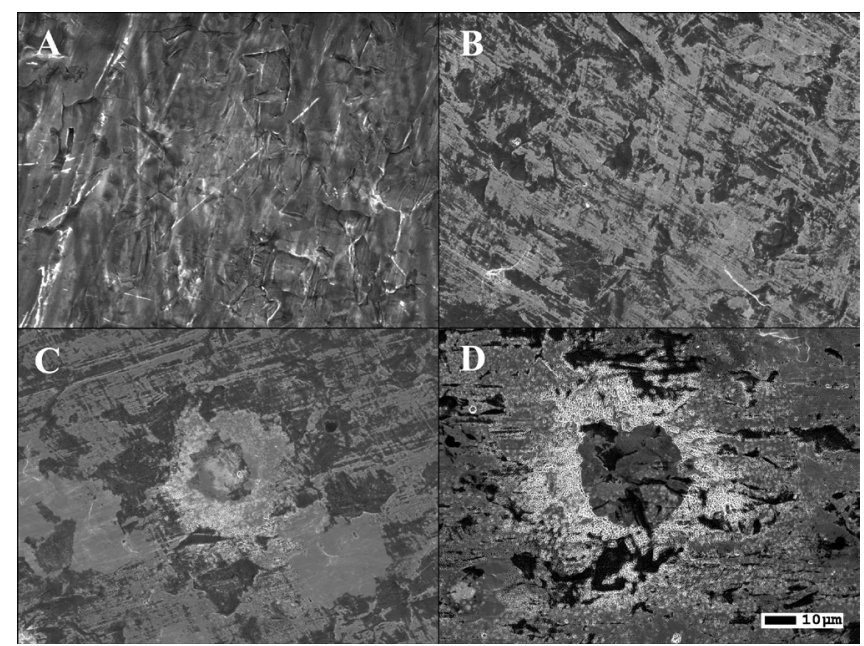

Figure 2. SEM microphotographs of Zn surface. (A) pretreated Zn previous to its immersion in $\mathrm{KClO}_{4} ;(B),(C),(D), \mathrm{Zn}$ anodically polarised in $0.1 \mathrm{M}$ $\mathrm{KClO}_{4}$ at $-800,-600,-400 \mathrm{mV}$ vs. SCE, respectively, for $1 \mathrm{~min}$
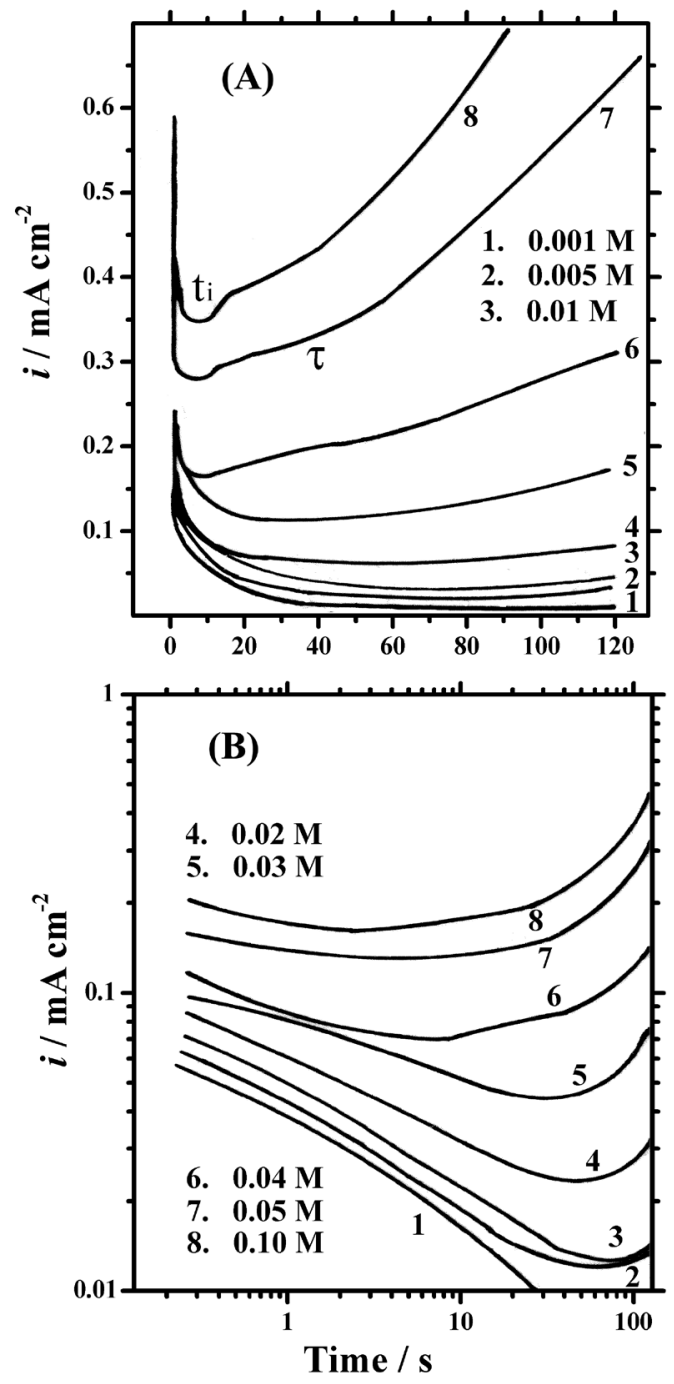

Figure 3. Potentiostatic current-time transients for $\mathrm{Zn}$ in $\mathrm{KClO}_{4}$ solutions with different concentrations at $-950 \mathrm{mV}$ (vs. SCE) and $25^{\circ} \mathrm{C}$ in linear (A) and logarithmic $(B)$ scales 
Inspection of the recorded results reveals that at low electrolyte concentration $(\leq 0.01 \mathrm{M})$, the current decreases very rapidly with time to attain a steady state current value. The decrease in the transient current, $i$, is related to the growth of a $\mathrm{ZnO}$ layer on the electrode surface. ${ }^{18-20}$ The film growth kinetics fits the model proposed by Macdonald et al. ${ }^{16,21}$ which is given by:

$i=\mathrm{A} \mathrm{t}^{-\mathrm{n}}$

where $\mathrm{A}$ and $\mathrm{n}$ are constants depending upon the potential limit $\mathrm{E}_{\mathrm{a}}$ and the electrolyte concentration. The value of $\mathrm{n}$ represents the $\mathrm{ZnO}$ growth rate $^{22}$ and is given by the slope of the descending part of the $\log i-\log t$ relationship (Figure 3B). The data given in Table 1 show that the values of $n$ decrease with increasing electrolyte concentration $\left[\mathrm{KClO}_{4}\right]$. This means that as the $\mathrm{KClO}_{4}$ concentration increases, the growth rate of $\mathrm{ZnO}$ decreases. This aggressiveness of the $\mathrm{ClO}_{4}^{-}$species, already discussed in the Introduction section, is well reported in the literature. ${ }^{23-26}$ Favouring reaction (1), weakens the passive layer, which breaks and promotes pit initiation and growth. Considering that chemical analysis did not detect any traces of $\mathrm{Cl}^{-}$after each experimental run, it can be assumed that reaction (1), although very aggressive towards the $\mathrm{ZnO}$ passive layer, is kinetically hindered. At concentrations higher than about $0.005 \mathrm{M}$, the current transient initially decreases to a minimum value $i_{\mathrm{m}}$ at a characteristic pitting time parameter $\mathrm{t}_{i}$ (incubation time). In other words, at low concentrations $(\sim 0.001-0.005 \mathrm{M})$ the passive layer grows very quickly and pitting corrosion is not induced. At moderate and higher concentrations passive layer growth occurs followed by a current increase that indicates pitting nucleation and growth. ${ }^{27-29}$ The reciprocal of the incubation time $\left(\mathrm{t}_{i}^{-1}\right)$ is taken as the rate of pit nucleation. After $t_{i}$, the current transient exhibits two straight lines with two different slopes. The time at the inflection point is denoted as the induction time $(\tau)$. The first straight line may be considered to correspond to the period of pit nucleation, while the second line to that of pit growth. ${ }^{30}$ The increase of current transient after $t_{i}$ can be represented by the Engell-Stolica equation for pitting corrosion: ${ }^{17}$

$i=\mathrm{B} \mathrm{t}{ }^{\mathrm{b}}$

where $\mathrm{B}$ and $\mathrm{b}$ are constants depending upon the applied potential and the concentration of $\mathrm{KClO}_{4}$. The slopes of the $\log i-\log \mathrm{t}$ curves after $\mathrm{t}_{i}\left(\mathrm{~b}_{1}\right.$ for the first line and $b_{2}$ for the second line) as well as the pit nucleation rate $\left(t_{i}^{-1}\right)$ and $i_{m}$ for various $\mathrm{KClO}_{4}$ concentrations are given in Table 1 .

The values of $b_{1}$ are nearly constant, while those of $b_{2}, t_{i}^{-1}$ and $i_{\mathrm{m}}$ increase with increasing perchlorate concentration. Moreover, current-time transient curves were recorded at various potential limits $\mathrm{E}_{\mathrm{a}}$ for a given electrolyte concentration. Figure 4 represents

Table 1. Effect of $\mathrm{KClO}_{4}$ concentration on the transient behaviour of $\mathrm{Zn}$ in $\mathrm{KClO}_{4}$ solutions at $-950 \mathrm{mV} v s$. SCE for passive layer growth $(\mathrm{n})$, pit nucleation $\left(\mathrm{b}_{1}, \mathrm{t}_{i}^{-1}\right.$ and $\left.i_{\mathrm{m}}\right)$ and its growth $\left(\mathrm{b}_{2}\right)$

\begin{tabular}{lccccc}
\hline$\left[\mathrm{KClO}_{4}\right](\mathrm{M})$ & $\mathrm{n}$ & $\mathrm{b}_{1}$ & $\mathrm{~b}_{2}$ & $\mathrm{t}_{i}^{-1}\left(\mathrm{~s}^{-1}\right)$ & $i_{\mathrm{m}}\left(\mathrm{mAcm}^{-2}\right)$ \\
\hline 0.001 & 0.450 & - & - & - & - \\
0.005 & 0.395 & - & 0.120 & 0.010 & 0.015 \\
0.01 & 0.355 & - & 0.165 & 0.016 & 0.035 \\
0.02 & 0.305 & - & 0.330 & 0.020 & 0.060 \\
0.03 & 0.225 & - & 0.549 & 0.030 & 0.100 \\
0.04 & 0.185 & 0.0991 & 0.575 & 0.138 & 0.160 \\
0.05 & 0.150 & 0.0918 & 0.590 & 0.195 & 0.270 \\
0.10 & 0.145 & 0.0998 & 0.625 & 0.251 & 0.336 \\
\hline
\end{tabular}

some transients on linear (a) and logarithmic (b) scales for $\mathrm{Zn}$ in $0.1 \mathrm{M} \mathrm{KClO}_{4}$ solution at $\mathrm{E}_{\mathrm{a}}$ potentials ranging from $-1100 \mathrm{mV}$ to -950 mV (vs. SCE).

For anodic potentials in the lower limits of the passive region, the rapid decrease of $i$ to a steady value means that only the $\mathrm{ZnO}$ film is formed. For anodic potentials higher than about $-1000 \mathrm{mV} v s$. SCE, $\mathrm{ZnO}$ growth as well as pit nucleation and growth occur. Table 2 lists the values of $\mathrm{n}, \mathrm{b}_{1}, \mathrm{~b}_{2}, \mathrm{t}_{i}^{-1}$ and $i_{\mathrm{m}}$ for the different anodic potentials
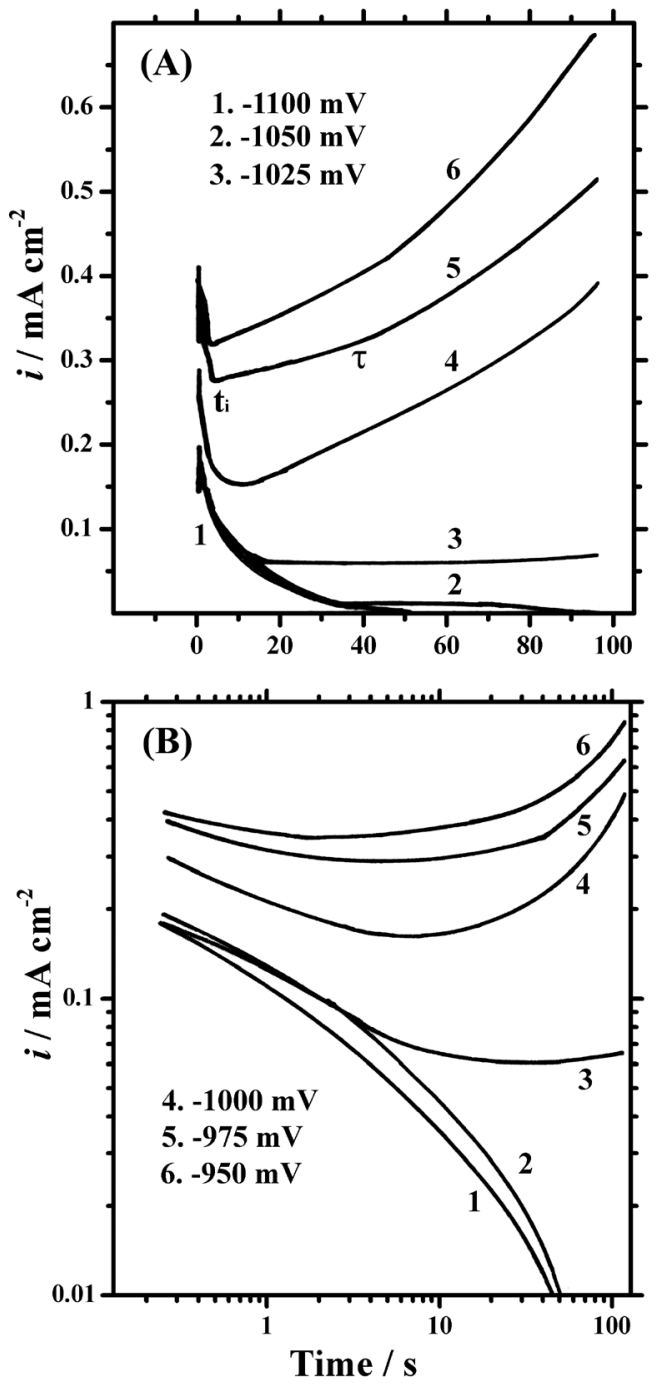

Figure 4. Potentiostatic current-time transients for $\mathrm{Zn}$ in $0.1 \mathrm{M} \mathrm{KClO}_{4}$ solutions at different anodic potentials and $25^{\circ} \mathrm{C}$ in linear $(A)$ and logarithmic (B) scales

Table 2. Effect of applied anodic potential on the transient behaviour of $\mathrm{Zn}$ in $0.1 \mathrm{M} \mathrm{KClO}_{4}$ solutions at $25^{\circ} \mathrm{C}$ for passive layer growth (n), pit nucleation $\left(\mathrm{b}_{1}, \mathrm{t}_{i}^{-1}\right.$ and $\left.i_{\mathrm{m}}\right)$ and its growth $\left(\mathrm{b}_{2}\right)$

\begin{tabular}{lccccc}
\hline $\mathrm{E}_{\mathrm{a}}(\mathrm{mV})$ & $\mathrm{n}$ & $\mathrm{b}_{1}$ & $\mathrm{~b}_{2}$ & $\mathrm{t}_{i}^{-1}\left(\mathrm{~s}^{-1}\right)$ & $i_{\mathrm{m}}\left(\mathrm{mA} \mathrm{cm} \mathrm{cm}^{-2}\right)$ \\
\hline-1100 & 0.450 & - & - & - & - \\
-1050 & 0.355 & - & - & - & - \\
-1025 & 0.320 & - & 0.050 & 0.045 & 0.060 \\
-1000 & 0.285 & - & 0.475 & 0.115 & 0.150 \\
-975 & 0.235 & 0.0942 & 0.515 & 0.225 & 0.230 \\
-950 & 0.145 & 0.0998 & 0.625 & 0.251 & 0.336 \\
\hline
\end{tabular}


used to obtain the results given in Figure 4. The values of $n$ decrease with increasing applied potential, the values of $b_{1}$ are nearly constant, while those of $\mathrm{b}_{2}, \mathrm{t}_{i}^{-1}$ and $i_{\mathrm{m}}$ enhance with the potential limit $\mathrm{E}_{\mathrm{a}}$.

\section{CONCLUSIONS}

The corrosion behaviour of $\mathrm{Zn}$ in $\mathrm{KClO}_{4}$ solutions was studied by current-time transient measurements. Previous potentiodynamic curves exhibited active/passive transitions. Zinc passivation is due to the formation of a $\mathrm{ZnO}$ layer on the electrode surface. Higher concentrations of $\mathrm{ClO}_{4}^{-}$ions $(>0.005 \mathrm{M})$ break down the passive layer and cause pitting corrosion at a certain anodic potential. The rate of pit nucleation increases with increasing both $\mathrm{ClO}_{4}{ }_{4}^{-}$concentration and applied anodic potential.

\section{ACKNOWLEDGEMENTS}

The authors would like to thank José A. D. Condeço for his help with the SEM measurements.

\section{REFERENCES}

1. Morgan, S. W. K.; Zinc and its Alloys and Compounds, Wiley: New York, 1985.

2. Zhang, X. G.; Corrosion and Electrochemistry of Zinc, Plenum: New York, 1996.

3. McKrube, M. C. H.; Macdonald, D. D.; J. Electrochem. Soc. 1981, 128, 524.

4. Kim, J. T.; Jorné, J.; J. Electrochem. Soc. 1980, 127, 7.

5. Baugh, L. M.; Electrochim. Acta 1979, 24, 657.

6. Deslouis, C.; Duprat, M.; Tulet-Tournillon, C.; Corros. Sci. 1989, 29, 13.

7. Hamnett, H.; Mortimer, R. J.; J. Electroanal. Chem. 1987, 234, 185.

8. Láng, G.; Inzelt, G.; Vrabecz, A.; Horányi, G.; J. Electroanal. Chem. 2005, 582, 249.

9. Láng, G.; Horányi, G.; J. Electroanal. Chem. 2003, 552, 197.
10. Sziráki, L.; Szöcs, E.; Philbáth, Zs.; Papp, K.; Kálmán, E.; Electrochim. Acta 2001, 46, 3743.

11. Justo, M. J.; Ferreira, M. G. S.; Corros. Sci. 1993, 34, 533.

12. Szklarska-Smialowska, Z.; Pitting Corrosion of Metals, NACE: Houston, 1986.

13. Sato, N.; Hashimoto, K., eds.; Passivity of Metals and Semiconductors, Pergamon: Oxford, 1990, part 1.

14. Kaesche, H.; Die Korrosion der Metalle, $3^{\text {rd }}$ ed., Springer-Verlag: Berlin, 1990

15. Frankel, G. S.; Scully, J. R.; Jahnes, C. V.; J. Electrochem. Soc. 1996, 143, 1834.

16. Macdonald, D. D.; Urquidi-Macdonald, M.; J. Electrochem. Soc. 1990, $137,2395$.

17. Engell, H. J.; Stolica, D. N.; Z. Phys. Chem. Unterr. 1959, $20,113$.

18. Sziráki, L.; Cziráki, A.; Geröcs, I.; Vértesy, Z.; Kiss, L.; Electrochim. Acta 1998, 43, 175

19. Triboulet, R.; Perrière, J.; Prog. Crystal Growth Char. Mat. 2003, 47, 65.

20. Chen, X. L.; Geng, X. H.; Xue, J. M.; Li, L. N.; J. Crystal Growth 2007, $299,77$.

21. Chao, C. Y., Lin, L. F.; Macdonald, D. D.; J. Electrochem. Soc. 1981, $128,1187$.

22. Kim, J.; Pyun, S.; Electrochim. Acta 1995, 40, 1863.

23. Ujvári, M.; Láng, G.; Horányi, G.; J. Appl. Electrochem. 2002, 32, 581.

24. Cachet, C.; Wiart, R.; J. Electroanal. Chem. 1981, 129, 103.

25. Cachet, C.; Ganne, F.; Maurin, G.; Petitjean, J.; Vivier, V.; Wiart, R.; Electrochim. Acta 2001, 47, 509.

26. Cachet, C.; Ganne, F.; Joiret, S.; Maurin, G.; Petitjean, J.; Vivier, V.; Wiart, R.; Electrochim. Acta 2002, 47, 3409.

27. Amin, M. A.; Electrochim. Acta 2005, 50, 1265.

28. Abd El Aal, E. E.; Corros. Sci. 2002, 44, 2041.

29. Assaf, F. H.; Abd El-Rehiem, S. S.; Zaky, A. M.; Mat. Chem. Phys. 1999, 58, 58

30. Milosev, I.; Metikos-Hukovic, M.; J. Electrochem. Soc. 1991, 138, 61. 